\title{
CONFIGURAÇÃO E ATRATIVIDADE DA CARREIRA DOCENTE DA EDUCAÇÃO BÁSICA DO MUNICÍPIO DE CAMETÁ/PA
}

\author{
CASTRO, José Joaquim Martins (Brasil, Belém, Pará) ${ }^{1 *}$; \\ CARVALHO, Fabrício Aarão Freire (Brasil, Belém, Pará) $)^{2 *}$ \\ ${ }^{1}$ Universidade Federal do Pará \\ ${ }^{2}$ Secretaria de Educação do Estado do Pará \\ https://orcid.org/0000-0003-4319-8777 \\ https://orcid.org/0000-0002-4753-2560
}

\section{RESUMO}

Objetiva-se analisar a configuração da carreira dos profissionais da educação básica no município de Cametá, Pará, quanto à presença de elementos de valorização docente e estímulo para uma melhor remuneração, atratividade e incentivo à permanência na carreira. A pesquisa foi realizada por meio de estudo bibliográfico e documental e revelou que as legislações nacionais que tratam da carreira do magistério no Brasil tiveram influência e foram determinantes para a implementação de normatizações no município. Embora a carreira docente da rede municipal de ensino de Cametá apresente alguns elementos de valorização, não estabelece regras relacionadas a melhores condições de trabalho docente e precisa resgatar a valorização social do profissional do magistério, estimulando a jornada de trabalho em uma única escola, com a garantia de progressão e percentual de aumentos estimulantes para atrair bons profissionais à carreira.

PALAVRAS-CHAVE: Educação básica. Valorização do magistério. Plano de carreira docente.

\section{CONFIGURATION AND ATTRACTIVENESS OF THE TEACHER CAREER OF THE BASIC EDUCATION OF THE MUNICIPALITY OF CAMETÁ/PA}

\section{ABSTRACT}

The aim of the research was to analyze the configuration of the career of basic education professionals, in the municipality of Cametá, Pará, regarding the presence of elements of teacher appreciation and encouragement for a better remuneration, attractiveness and incentive to career. The research was carried out through a bibliographical and documentary study and revealed that the national legislations that deal with the teaching career in Brazil had influence and were determinant for the implementation of norms in the municipality. However, although the teaching career of the municipal teaching network of Cametá, presents some elements of valorization, does not establish rules related to better working conditions of teachers and needs to rescue the social valuation of the professional of the teaching profession by stimulating the working day in a single school, with the guarantee of progression and percentage of stimulating increases to attract good professionals to the career.

KEYWORDS: Basic education. Valorization of the magisterium. Teaching career plan.

\section{CONFIGURACIÓN Y ATRACTIVIDAD DE LA CARRERA DOCENTE DE LA EDUCACIÓN BÁSICA DEL MUNICIPIO DE CAMETÁ/PA}

\section{RESUMEN}

La investigación tuvo por objetivo analizar la configuración de la carrera de los profesionales de la educación básica en el municipio de Cametá, Pará, en cuanto a la presencia de elementos de valorización docente y estímulo para una mejor remuneración, atractivo e incentivo de permanencia en la carrera. La investigación fue realizada por medio de estudio bibliográfico y documental y reveló que las legislaciones nacionales que tratan de la carrera del magisterio en Brasil tuvieron influencia y fueron determinantes para la implementación de normatizaciones en el municipio. Aunque la carrera docente de la red municipal de enseñanza de Cametá presente algunos elementos de valorización, no establece reglas relacionadas a mejores condiciones de trabajo docente y necesita rescatar la valorización social del profesional del magisterio estimulando la jornada de trabajo en una única escuela con la garantía de progresión y porcentual de aumentos estimuladores para atraer buenos profesionales a la carrera.

PALABRAS CLAVE: Educación básica. Valorización del magisterio. Plan de carrera docente. 


\section{INTRODUÇÃO}

Esta pesquisa buscou entender as normatizações legais da área da educação e suas implicações na carreira dos profissionais do magistério público do município de Cametá, localizado no coração da Amazônia, na Região de Integração do Tocantins, Pará. Nesse município, o processo de discussão sobre a implantação de Plano de Cargos, Carreira e Remuneração (PCCR) ganhou força a partir de 1998, com a adesão do município ao Termo de Convênio de Municipalização do Ensino, algo, portanto, que precisava ser mais bem investigado.

Este artigo tem como objetivo geral analisar, por meio de estudo documental das legislações nacionais e municipais que tratam da carreira docente, a configuração da carreira dos professores da rede pública de educação básica do município paraense de Cametá a partir das regulamentações legais de âmbito municipal vigentes, em especial o PCCR (Lei n. 212/2012), visando identificar possíveis contribuições para uma carreira no magistério municipal mais atrativa e condigna.

O estudo da literatura da área se fez necessário para que fosse possível compreender e fundamentar a construção de um arcabouço teórico sobre a carreira dos professores da educação básica em nível municipal identificadas nas políticas educacionais em voga no Brasil.

Este artigo encontra-se estruturado em cinco seções. A primeira é esta Introdução, em que foram apresentados aspectos relacionados ao objetivo e à metodologia empregada neste estudo. A segunda apresenta informações que ajudam a compreender o contexto de implementação do PCCR do município de Cametá. A terceira aborda a discussão teórico-conceitual acerca da carreira docente e planos de carreira. A quarta caracteriza a carreira docente do município de Cametá no que se refere ao critério de ingresso na carreira, forma de progressão, vencimento/ remuneração, jornada de trabalho, estímulo à formação e condições de trabalho. Por fim, a quinta e última seção traz as considerações finais. 


\title{
2 O CONTEXTO DE IMPLEMENTAÇÃO DO PCCR NO MUNICÍPIO DE CAMETÁ/PA
}

No município de Cametá, local onde se desenvolveu esta pesquisa, o incremento e a implementação do processo de investimentos na educação básica se deu efetivamente após o processo de municipalização do ensino ${ }^{1}$, que ocorreu no ano de 1998, com a adesão desse município. É a partir desse processo de municipalização e da implantação do Fundef, em 1996, que a educação fundamental (hoje educação básica) passa a ser administrada pelo governo municipal. Tal processo tem sido apontado como um dos efeitos do Fundef/Fundeb na educação no estado do Pará (CARVALHO, 2012; GEMAQUE, 2004; GUTIERRES, 2010).

Entender o contexto histórico da adesão ao processo de municipalização da educação (1998), da implantação do Fundef (1996) e do Fundeb (2006), do Piso Salarial Nacional (2008), das Resoluções do CNE/CEB n. 3/1997, n. 2/2009 e n. 5/2010 e os PCCRs (Leis n. 66/2006, n. 212/2012 e n. 256/2013) do município se faz necessário e importante para quem pretende estudar/pesquisar e evidenciar as possíveis repercussões/efeitos na carreira dos profissionais da educação básica da rede municipal de ensino de Cametá, pois, segundo Silva (2010, p. 28):

\begin{abstract}
Para compreender como está sendo implementada a política salarial para os profissionais da educação básica preconizada nas legislações, é necessário não apenas olhar os documentos, mas compreender os aspectos históricos, culturais, sociais e econômicos, ou seja, as múltiplas determinações que permeiam a realidade em que a política é implementada.
\end{abstract}

É que todas essas normas legais, de forma interligada, implicam diretamente sobre a carreira e a remuneração dos professores, além da qualidade da educação. Para entender esse processo, busca-se analisar historicamente a legislação municipal, que trata direta ou indiretamente da carreira dos profissionais do magistério no município de Cametá. O período pesquisado compreendeu os anos de 2006 a 2013, fazendo uma volta no tempo aos idos de 1998, quando do processo de municipalização da educação.

1 Implantada a partir de 1997 pelo governo de Almir Gabriel, a política de municipalização da educação no estado do Pará tomou impulso com a política de fundos - Fundo de Manutenção e Desenvolvimento do Ensino Fundamental e de Valorização do Magistério (Fundef) e Fundo de Manutenção e Desenvolvimento da Educação Básica e de Valorização dos Profissionais da Educação (Fundeb) -, iniciada no governo de Fernando Henrique Cardoso (FHC) e com continuidade no governo de Lula. Esse processo consistiu na transferência - do governo estadual para os governos municipais - de responsabilidades de decisão e execução de serviços educacionais do ensino fundamental.

Educação \& Formação, Fortaleza, v. 4, n. 10, p. 164-179, jan./abr. 2019

DOI: https://doi.org/10.25053/redufor.v4i10.849

http://seer.uece.br/redufor 
Os documentos analisados formam um arcabouço jurídico legal e serviram de base para esta pesquisa.

\section{DA DEFINIÇÃO DA CARREIRA DO MAGISTÉRIO E O PCCR}

Para Abreu e Balzano (1998a, 1998b) e Silva (2014), o uso da palavra "carreira" vem se adequando ao longo do tempo e conforme as circunstâncias e necessidades, de modo a atender ao processo de valorização dos profissionais do magistério e de outras profissões. Portanto, a carreira do profissional do magistério está intimamente ligada à evolução de sua vida funcional, que pode se dar por tempo de serviço ou nível de formação, trazendo-Ihe valorização, desenvolvimento profissional e retorno financeiro. No entanto, para melhor atender e proporcionar valorização aos profissionais do magistério, fez-se necessário estruturar e normatizar, de forma a regulamentar esses elementos em um documento, o PCCR.

Consoante Abreu e Balzano (1998a), o Plano de Carreira apresenta elementos de evolução na carreira profissional e dispõe de instrumentos que valorizam o bom funcionário, sendo que, "[...] para o servidor, a carreira constitui direito à progressão profissional regulamentada, e ele pode ocupar sucessivas posições em graus crescentes de importância, remuneração e responsabilidades" (ABREU; BALZANO, 1998b, p. 221). Esses mesmos autores conceituam Plano de Carreira como o conjunto de normas que define e regula as condições e o processo de movimentação dos integrantes em uma determinada carreira, estabelecendo a progressão funcional e a correspondente evolução da remuneração. Porém, esses mesmos estudos informam que vários critérios e fatores devem ser considerados quando se trata de valorizar os profissionais do magistério, sendo o PCCR uma forma de organizar a carreira, constituindo-se em meio ou forma de incentivo ao servidor, estabelecendo, entre outros fatos, que:

\footnotetext{
Os cargos efetivos de determinada atividade profissional no serviço público podem ser isolados ou organizados em posições escalonadas, isto é, em carreira. A organização de uma carreira implica a distribuição dos cargos efetivos em classes, que consistem em degraus da carreira, correspondentes a conjuntos de cargos iguais em responsabilidades e vencimentos. A passagem de uma classe para outra constitui uma forma de progressão, conhecida como promoção. Assim, progressão significa qualquer mudança de posição na carreira, e promoção implica mudança de classe. (PRASEM, 2001, p. 70, grifos do original).
}

Educação \& Formação, Fortaleza, v. 4, n. 10, p. 164-179, jan./abr. 2019 
Verifica-se que o PCCR se constituiu em um importante instrumento de progressão na carreira, pois "[...] regulamenta e possibilita ao servidor [...] ocupar sucessivas posições em graus crescentes de importância, remuneração e responsabilidades" (ABREU; BALZANO, 1998b, p. 221), porém precisa avançar no sentido de estabelecer novas formas de evolução na carreira, rumo a uma melhor remuneração dos profissionais do magistério e consequentemente da qualidade da educação.

Para Abreu e Balzano (2001), a valorização do magistério, associada à sua profissionalização e à qualidade do ensino, passa por um processo que prevê maior qualificação e domínio de conhecimentos, os quais se revertem em melhor desempenho, logo, em maior remuneração. As respostas a essas preocupações foram dadas com a promulgação da Constituição Federal (CF) de 1988, na qual se reconheceu a desvalorização do profissional da educação e se propôs sua valorização como princípio da educação escolar (MONLEVADE, 2000). Em seu artigo 206, a CF estabelece que:

\footnotetext{
O ensino será ministrado com base nos seguintes princípios: [...] V- valorização dos profissionais da educação escolar, garantidos, na forma da lei, planos de carreira, com ingresso exclusivamente por concurso público de provas e títulos, aos das redes públicas. (BRASIL, 1988).
}

A valorização do profissional da educação e a construção de Plano de Carreira por estados e municípios, dois pontos estabelecidos neste artigo, têm como objetivo proporcionar a valorização da carreira, oferecendo condições dignas e melhor remuneração do profissional de educação como tentativa de reverter o processo de desvalorização do professor.

\section{A CONFIGURAÇÃO DA CARREIRA DO MAGISTÉRIO NO MUNICÍPIO DE CAMETÁ/PA NA LEI N. 212/2012 (PCCR/2012)}

A análise da estruturação ou configuração dessa referida lei, criada com o objetivo de atender às reivindicações dos profissionais da educação da rede pública de educação básica do município, tem como meta evidenciar como está configurada a carreira e se houve a valorização dos profissionais do magistério através da análise dos seguintes elementos: tipo de admissão/ingresso na carreira, formas de progressão/ 
evolução na carreira, vencimento e remuneração, jornada de trabalho, estímulo à formação e condições de trabalho.

\subsection{TIPO DE ADMISSÃO/INGRESSO NA CARREIRA}

Para ingresso na carreira dos profissionais da educação e composição do quadro permanente, o PCCR/2012, em seu artigo 3oㅡㄹ inciso VI, determina a realização de concurso público de provas e/ou provas e títulos para provimento de cargos efetivos. Esse PCCR, no seu artigo 20, define, em consonância com o Estatuto dos Funcionários Municipais, que o ingresso nas carreiras de profissionais da educação se dará exclusivamente por concurso público de provas e títulos, atendendo a uma demanda da atual Lei de Diretrizes e Bases da Educação Nacional (LDBEN), Lei n. 9.394/1996, e da Constituição Federal de 1988 (artigo 37, inciso II), pois se trata de um importante quesito para a valorização e qualificação dos profissionais da educação.

Quanto à oferta de concurso público, os artigos 21 e 22 determinam que o concurso para a área de magistério e área de serviço de apoio escolar será realizado por nível de habilitação e subárea de atuação, e o artigo 23 prevê que o ingresso de ambos se dará na classe "A", referência "1", da classe para a qual prestou o concurso. Ao ingressar na carreira, o profissional cumprirá estágio probatório de três anos e somente adquirirá estabilidade com a obtenção de resultado satisfatório na avaliação especial de desempenho, proferida por comissão constituída especificamente para tal fim, conforme Lei Municipal n. 65/2006 (Regime Jurídico Estatutário dos Servidores Públicos Civis do Município de Cametá/PA).

\subsection{FORMAS DE PROGRESSÃO/EVOLUÇÃO NA CARREIRA}

Para Dutra Júnior et al. (2000), progressão é a evolução na carreira, que pode ocorrer tanto pela mudança no valor do vencimento, dentro da mesma classe, chamada de progressão horizontal, quanto por promoção, que consiste na mudança para uma classe superior do mesmo cargo, chamada de progressão vertical, que, por se configurar como um dos elementos de valorização do profissional do magistério, ela foi assegurada no PCCR/2012. 
De acordo com o PCCR/2012, a carreira dos profissionais da educação está estruturada em duas áreas profissionais (magistério e serviço de apoio escolar) com três níveis, seis classes e seis referências para cada cargo (CAMETÁ, 2012). Assim como no Estatuto, o PCCR prevê, no artigo 27, a progressão através de promoções do profissional nos sentidos vertical e horizontal. Contudo, as promoções, tanto no sentido vertical como horizontal, somente ocorrerão após o período de três anos de estágio probatório e consequente aquisição da estabilidade, mediante resultado satisfatório na avaliação especial de desempenho (CAMETÁ, 2012).

Para ambas as áreas estabelecidas nessa lei, as promoções no sentido vertical da carreira acontecerão com a passagem do servidor de uma classe para a outra dentro do mesmo cargo, de acordo com a titulação acadêmica obtida, obedecendo às seguintes regulamentações:

I - do Nível 1 (Médio) para o nível 2 (Graduação) em função da aquisição, em caráter oficial, do diploma de graduação em licenciatura plena em pedagogia; curso normal superior; graduação plena para o magistério de educação infantil e anos iniciais do ensino fundamental; licenciatura para o magistério de educação infantil e anos iniciais do ensino fundamental; II - do Nível 2 (Graduação) para o nível 3 (Especialização), nos seguintes termos: a) para atuação nas Subáreas 1 e 2, em função da aquisição, em caráter oficial, do certificado de especialização nas áreas específicas da Pedagogia, com duração mínima de trezentos e sessenta horas; b) para atuação na Subárea 3, em função da aquisição, em caráter oficial, do certificado de especialização na área específica do currículo para a qual prestou concurso público, com duração mínima de trezentos e sessenta horas; III - da classe onde estiver para a imediatamente superior, através da avaliação periódica de desempenho, do conhecimento, aferição da qualificação e do efetivo tempo de exercício das funções próprias do cargo, conforme regulamento disposto em lei complementar. (CAMETÁ, 2012, artigo 28, incisos I e II).

Para a área do serviço de apoio escolar, dar-se-á progressão:

a) do nível 1 (Médio) para o nível 2 (Graduação) em função da aquisição, em caráter oficial, do diploma de nível superior, em graduação na subárea técnica específica para a qual prestou concurso público; b) do nível 2 (Graduação) para o nível 3 (Especialização), em função da aquisição, em caráter oficial, do certificado de especialização específica na subárea técnica para a qual tenha prestado concurso público; c) do subnível onde estiver para o imediatamente superior, através da avaliação periódica de desempenho, do conhecimento, aferição da qualificação e do efetivo tempo de exercício das funções próprias do cargo, conforme regulamento disposto em lei complementar. (CAMETÁ, 2012, artigo 30 , inciso I).

Quanto à promoção horizontal para ambas as áreas, de acordo com o artigo 29, acontecerá da referência onde estiver para a imediatamente superior em função do 
tempo de efetivo exercício (cinco anos) das funções próprias do cargo para o qual prestou concurso público e mediante resultado satisfatório na avaliação especial de desempenho (CAMETÁ, 2012, artigos 29 e 32, § 3). A promoção funcional é definida como sendo a passagem do servidor estável de seu padrão de vencimento para outro imediatamente superior, dentro da mesma classe.

\subsection{VENCIMENTO/REMUNERAÇÃO}

Sobre esse aspecto, é possível verificar que a vigente CF determina, em seu artigo 37 , inciso $X$, em conformidade com o artigo 39, $\S 4^{\circ}$, que a remuneração ou subsídio dos servidores públicos devem ser fixados ou alterados por lei específica e revisão anual, sempre na mesma data e sem distinção de índices. A revisão salarial anual dos profissionais do magistério tinha como objetivo preservar o poder de compra dos professores, sendo inclusive incorporada ao artigo 5ํㅗ inciso $\mathrm{VI}$, da Resolução n. 2/2009.

De acordo com o artigo 42 do PCCR/2012, a remuneração dos profissionais da educação corresponde ao vencimento relativo ao nível de habilitação, classe e referência em que se encontre acrescido das vantagens pecuniárias a que fizer jus, sempre calculadas sobre o vencimento-base do profissional, o qual, conforme o artigo 43, é o valor fixo da retribuição pecuniária pelo exercício das funções próprias do cargo investido, correspondente à natureza e complexidade delas, nível e classe em que esteja. Assim, o PCCR de Cametá considera como o vencimento-base da carreira o fixado para a classe "A" do nível 1 de cada área profissional e cargo, sendo o vencimento-base inicial, para a área de magistério (médio), $R \$ 1.052,24$. Para professor nível 2 (superior), o vencimento-base inicial de $R \$ 1.579,36$. Para professor nível 3 (especialização), estabeleceu-se um vencimento-base inicial de $R \$ 1.683,58$ e vencimento final de $\mathrm{R} \$ 2.110,13$.

Além do vencimento, o PCCR/2012 também prevê gratificações não cumulativas calculadas sobre o vencimento-base do profissional de cada área de acordo com o nível de habilitação e a jornada de 40 horas. No caso do exercício da docência, em classes exclusivas de educação especial, a gratificação será de $20 \%$ de acordo com o nível de habilitação e para os cargos comissionados DAS III, II e I a gratificação será de 50\%, 
40\% e 30\%, respectivamente. Também serão gratificadas as seguintes funções: diretor, vice-diretor, secretário-geral de unidade escolar e suporte pedagógico, de acordo com o porte da escola: grande, média ou pequena. Com gratificação de 50\%, 40\% e 30\%, do vencimento-base, respectivamente.

O PCCR/2012 prevê ainda, no artigo 56 e no $\S 1^{\circ}$ desse mesmo artigo, adicional por tempo de efetivo exercício das funções próprias do cargo, que será de 1,25\% por ano, calculado sobre o vencimento-base do profissional, no limite máximo de $35 \%$ até o final da carreira, sendo pago a cada período de quatro anos (quadriênio), independentemente de requerimento do servidor. A Lei n. 212/2012 prevê no artigo 57 também o adicional de $30 \%$ pelo trabalho em regime de dedicação exclusiva, que se dará na proporção de $1 / 30$, se professor, e de $1 / 25$, se professora ${ }^{2}$, por ano de percepção da vantagem.

Além de ser previsto também o adicional por titularidade, que será pago ao profissional da educação em função da aquisição do certificado de pós-graduação em níveis de mestrado (15\%) e doutorado (30\%), ambos na subárea de atuação para a qual prestou concurso público (percentuais alterados pela Lei n. 256/2013). Já o adicional por promoção de classe (artigo 59) será pago no percentual de $10 \%$ e incorporado ao vencimento-base do profissional da educação a cada promoção.

Os pagamentos dos mais variados tipos de gratificações passaram a fazer parte da realidade salarial dos profissionais do magistério. Para Abreu (2011), a remuneração dos professores, em geral, é composta por vários tipos de gratificações e foram superdimensionadas em seus valores e usadas como estratégia para compensar o baixo vencimento pago a esses profissionais. Meirelles (1990) vê com preocupação a utilização desse dispositivo, visto que são de natureza transitória e não se incorporam automaticamente ao vencimento no momento da aposentadoria.

\subsection{JORNADA DE TRABALHO}

De acordo com o capítulo III, seção I, da Lei n. 212/2012, a jornada de trabalho do professor em função docente será de, no mínimo 30, e no máximo, 40 horas

2 Encontra-se aqui disparidade de valores, o que pode ser considerado como injustiça pautada na diferença de gênero.

Educação \& Formação, Fortaleza, v. 4, n. 10, p. 164-179, jan./abr. 2019

DOI: https://doi.org/10.25053/redufor.v4i10.849

http://seer.uece.br/redufor 
semanais, sendo que esse total inclui $2 / 3$ de horas de aula efetiva com o aluno e 1/3 de horas (10 e 13 horas, respectivamente) em atividades extraclasses, essas últimas destinadas, de acordo com a proposta pedagógica da escola, à preparação e avaliação do trabalho didático, à colaboração com a administração da escola, às reuniões pedagógicas, à articulação com a comunidade e ao aperfeiçoamento profissional, consoante a proposta pedagógica da escola (CAMETÁ, 2012, artigo 31, §§ 1ํㅜ e 3ํ).

Já para os professores que atuam nos anos finais do ensino fundamental em quaisquer de suas modalidades, será de 30 horas semanais, lembrando que aos profissionais com disponibilidade para jornada de 40 horas semanais poderá ser concedido o adicional de dedicação exclusiva. Quanto à jornada de trabalho do professor no exercício das funções de suporte pedagógico direto à docência e dos profissionais da área de serviço de apoio escolar, será de 40 horas semanais (artigos 38 e 41).

Verifica-se, nesta análise, que o PCCR/2012, no que tange à jornada de trabalho, coaduna-se com as determinações estabelecidas pela Lei Federal n. 11.738/2008 (Lei do Piso), em seu artigo $2^{\circ}$, $§ 4^{\circ}$, e atende ainda a determinações estabelecidas na vigente LDBEN (artigos 13 e 14) e Parecer CNE/CEB n. 18/2012.

\subsection{ESTÍMULO À FORMAÇÃO}

O estímulo à formação e/ou ao aprimoramento profissional é incentivado dentro do PCCR/2012, na seção V, Da Qualificação Profissional. Em seu artigo 33, é assegurada a qualificação profissional aos profissionais da educação básica da rede municipal de Cametá, objetivando o aprimoramento permanente do ensino e dos serviços de apoio escolar, bem como da progressão nas carreiras, por meio de cursos de formação, aperfeiçoamento e de outras atividades de atualização profissional.

A licença para aperfeiçoamento profissional consiste no afastamento do profissional da educação de suas funções, computado o tempo de afastamento para todos os fins de direito (artigo 34). A licença para aperfeiçoamento profissional será concedida para frequência a cursos de qualificação, formação, aperfeiçoamento, habilitação, especialização, mestrado e doutorado na área e subárea para a qual prestou concurso público (artigo 34, § $1^{\circ}$ ).

Educação \& Formação, Fortaleza, v. 4, n. 10, p. 164-179, jan./abr. 2019 
Os cursos deverão ser ofertados por instituições credenciadas com cursos devidamente autorizados ou reconhecidos. É possível verificar ainda que o deferimento da licença dependerá do número de licenciados por período e impacto financeiro causado pelas substituições. Já o aporte financeiro dependerá da viabilidade financeira do cofre público municipal. Outro elemento evidenciado é a necessidade da existência de profissionais devidamente habilitados para a substituição temporária, integral ou parcial do licenciado. O profissional beneficiado com a licença deverá obrigatoriamente desempenhar as funções inerentes ao cargo, pelo período mínimo de dois anos, na rede de ensino municipal pública de Cametá (artigo 34 , § 8). O profissional licenciado, conforme os artigos 33 e 34 , somente fará jus à nova licença um ano após o retorno às suas atividades.

\subsection{CONDIÇÕES DE TRABALHO}

As condições de trabalho do profissional do magistério público não devem estar dissociadas da jornada de trabalho, pois elas, de forma interligada, valorizam os profissionais da educação e influenciam na qualidade do trabalho, inclusive encontram-se definidas na LDBEN 1996 (artigo 67, inciso VI) como um dos indicadores de valorização profissional e garantia adequada de trabalho.

O Parecer n. 9/2009³ do CNE também considera necessário avançar no sentido de que os entes federados, por meio de normas ou leis, instituam parâmetros adequados à composição das classes, visando a garantir qualidade ao trabalho do professor. $O$ PCCR/2012, nesse contexto, faz referência somente ao período de férias anuais dos profissionais da educação no artigo 64, ao estabelecer que:

I - se professor, em função docente, de quarenta e cinco dias; II - se professor,
nas demais funções de magistério, de trinta dias; III - se profissional da educação
da Área de Serviço de Apoio Escolar, de trinta dias. Parágrafo único. As férias e
recesso do titular de cargo de professor no exercício da docência serão
concedidos da seguinte forma: I - trinta dias no mês das férias constitucional,

3 Esse parecer estabelece em cada escola, no máximo, uma média de estudantes por sala nos seguintes parâmetros: de 6 a 8 alunos por professor, para turmas de educandos de 0 a 2 anos de idade; até 15 alunos por professor para turmas de educandos de 3 a 10 anos de idade; até 20 crianças por professor para turmas de educandos de 4 a 5 anos de idade; nos anos iniciais do ensino fundamental, até 25 alunos por sala; nos anos finais do ensino fundamental, até 30 alunos por sala; e, no ensino médio, até 35 alunos por sala.

Educação \& Formação, Fortaleza, v. 4, n. 10, p. 164-179, jan./abr. 2019

DOI: https://doi.org/10.25053/redufor.v4i10.849

http://seer.uece.br/redufor 
preferencialmente no mês de julho, exceto quando o atendimento ao calendário letivo requerer de forma diversa; II - quinze dias no período do recesso escolar. (CAMETÁ, 2012, p. 10).

No que refere às condições de trabalho, o PCCR/2012 não se apresenta adequado a outros elementos que se deve considerar como tal, pois as condições de trabalho não se restringem apenas ao local, ao ambiente no qual o trabalho se desenvolve ou ao espaço onde ocorre a realização do processo de trabalho. Para Oliveira e Assunção (2010), as condições de trabalho se referem a um conjunto que inclui relações, as quais dizem respeito ao processo de trabalho e às condições de emprego (formas de contratação, remuneração, carreira e estabilidade).

\section{CONSIDERAÇÕES FINAIS}

O desafio de pesquisar um dos elementos de valorização dos profissionais do magistério da educação básica e os caminhos percorridos por esse processo de consolidação de uma política educacional no Brasil, como a "Carreira do Magistério", faz-se necessário como forma de buscar entender e compreender o secular descaso da União, estados e municípios pelo processo de valorização da educação, principalmente nos municípios, onde a implementação das políticas de fundos (Fundef e Fundeb) responsabilizou esse ente federado pela principal fase de formação do aluno e demais despesas com manutenção e desenvolvimento do ensino básico.

As análises empreendidas a partir da bibliografia estudada (ARELARO, 2004; CARVALHO, 2012; OLIVEIRA, 2010; PINTO, 2009) e das leis municipais permitiram constatar que as determinações legais aprovadas demarcam aspectos relevantes para a configuração de uma carreira mais atraente, pois estabeleceram relações funcionais entre os servidores municipais e a administração pública municipal.

A análise permitiu identificar os seguintes aspectos relevantes: tipo de admissão/ingresso via concurso público de provas e títulos; formas de progressão/evolução na carreira, levando em conta o tempo de serviço, nova titulação, formação continuada e avaliação por desempenho; vencimento e remuneração, equiparados com os de outros profissionais com formação semelhante e não inferior ao Piso Salarial Profissional Nacional (PSPN); jornada de trabalho de no máximo 40 horas semanais, hora-atividade para o desempenho de atividades extrassala de aula, incentivo

Educação \& Formação, Fortaleza, v. 4, n. 10, p. 164-179, jan./abr. 2019

DOI: https://doi.org/10.25053/redufor.v4i10.849

http://seer.uece.br/redufor 
à dedicação exclusiva; estímulo à formação e licença remunerada para capacitação do professor.

Em observância a esses preceitos legais, o PCCR/2012, em vigência no município de Cametá, estabelece o ingresso mediante concurso público de provas e títulos; movimentação na carreira por meio de promoção e por progressão; vencimento básico inicial de $R \$ 1.052,24$ e final de $R \$ 1.498,70$, para o professor de nível 1 (médio), vencimento-base inicial de $R \$ 1.579,36$ e vencimento final $R \$ 2.004,91$ para o professor de nível 2 (graduação), além de vencimento-base inicial de $R \$ 1.683,58$ e vencimento final de $R \$ 2.110,13$ para o professor de nível 3 (especialista), estabelecido pela Lei Municipal n. 256/2013, para uma jornada de trabalho de 30 horas semanais, mais gratificações, adicionais e licença remunerada para formação de, no máximo, três anos, podendo ser prorrogado por mais um ano.

Para além da existência e observância dos aspectos de valorização profissional pelos planos de carreira docente, faz-se necessário avaliar de que forma aparecem no corpo da lei e o quanto, em termos percentuais e financeiros, é acrescido à remuneração dos professores com as progressões, titulações, com sua materialização. A carreira do magistério dos profissionais da rede municipal de educação básica de Cametá, embora contemple elementos indicadores de valorização docente, não estabelece regras relacionadas a melhores condições de trabalho docente.

A incorporação de importantes demandas da categoria docente, garantidas no âmbito da legislatura nacional e aprovadas no contexto recente da política de fundos, ademais de inseridas no corpo da legislação municipal de Cametá, que trata da carreira, precisa resgatar a valorização social do profissional do magistério, jornada de trabalho em uma única escola, com a garantia de progressão e percentual de aumentos estimuladores para atrair bons profissionais à carreira, conferindo-Ihes remuneração condigna.

Foi possível perceber que a Lei Municipal n. 212/2012 trouxe alguns avanços para a carreira dos profissionais do magistério da educação básica do município de Cametá, no Pará, porém ainda há muito a se fazer no sentido de avançar rumo à implementação de uma carreira condigna e atrativa para a permanência de bons profissionais do magistério na carreira.

Educação \& Formação, Fortaleza, v. 4, n. 10, p. 164-179, jan./abr. 2019 


\section{REFERÊNCIAS}

ABREU, M. Carreira do professor. 2011. Mimeografado.

ABREU, M.; BALZANO, S. Plano de carreira e remuneração do magistério público. Brasília, DF: MEC, 1998a.

ABREU, M.; BALZANO, S. Progressão na carreira do magistério e avaliação de desempenho. Brasília, DF: MEC, 1998b.

ABREU, M.; BALZANO, S. Progressão na carreira do magistério e avaliação de desempenho. In: RODRIGUES, M. M.; GIÁGIO, M. (Org.). Guia de consulta para o Programa de Apoio aos Secretários Municipais de Educação - Prasem. Brasília, DF: MEC, 2001. p. 217-235.

ARELARO, L. R. G. Os fundos públicos no financiamento da educação - o caso Fundeb: justiça social, equívoco político ou estratégia neoliberal? 2004. Tese (Livre-Docência em Política e Organização da Educação Básica I e II) - Programa de Pós-Graduação em Política e Organização da Educação Básica I e II, Universidade de São Paulo, São Paulo, 2004.

BRASIL. Conselho Nacional de Educação. Resolução n. 2/2009 e Parecer CNE/CEB n. 9/2009. Diretrizes Nacionais para os Novos Planos de Carreira e de Remuneração para o Magistério dos Estados, do Distrito Federal e dos Municípios. Brasília, DF: MEC, 2009.

BRASIL. Constituição de 1988. Constituição da República Federativa do Brasil. Diário Oficial [da] República Federativa do Brasil, Poder Executivo, Brasília, DF, 5 out. 1988.

BRASIL. Lei n. 9.394, de 20 de dezembro de 1996. Estabelece as Diretrizes e Bases da Educação Nacional. Diário Oficial [da] República Federativa do Brasil, Poder Executivo, Brasília, DF, 21 dez. 1996.

BRASIL. Lei n. 9.424, de 24 de dezembro de 1996. Dispõe sobre o Fundo de Manutenção e Desenvolvimento do Ensino Fundamental e de Valorização do Magistério, na forma prevista no art. $60, \S 7^{\circ}$, do Ato das Disposições Constitucionais Transitórias, e dá outras providências. Diário Oficial [da] República Federativa do Brasil, Poder Executivo, Brasília, DF, 26 dez. 1996.

BRASIL. Lei n. 11.494, de 20 de junho de 2007. Regulamenta o Fundo de Manutenção e Desenvolvimento da Educação Básica e de Valorização dos Profissionais da Educação - Fundeb, de que trata o art. 60 do Ato das Disposições Constitucionais Transitórias; altera a Lei n. 10.195, de 14 de fevereiro de 2001; revoga dispositivos das Leis n. 9.424, de 24 de dezembro de 1996, 10.880, de 9 de junho de 2004, e 10.845, de 5 de março de 2004; e dá outras providências. Diário Oficial [da] República Federativa do Brasil, Poder Executivo, Brasília, DF, 21 jun. 2007. 
BRASIL. Lei n. 11.738, de 16 de julho de 2008. Regulamenta a alínea "e" do inciso III do caput do art. 60 do Ato das Disposições Constitucionais Transitórias, para instituir o piso salarial profissional nacional para os profissionais do magistério público da educação básica. Diário Oficial [da] República Federativa do Brasil, Poder Executivo, Brasília, DF, 17 jul. 2008.

CAMETÁ. Lei Municipal n. 212/2012, de 21 de maio de 2012. Dispõe sobre a adequação da carreira da área de magistério e criação unificada do Plano de Cargos, Carreiras e Remuneração dos Profissionais da Educação Básica do município de Cametá/PA. Diário Oficial do Município de Cametá, Poder Executivo, 22 maio 2012.

CARVALHO, F. A. F. Financiamento da educação: do Fundef ao Fundeb - repercussões da política de Fundos na Valorização Docente da Rede Estadual de Ensino do Pará 1996 a 2009. 2012. 267 f. Tese (Doutorado em Educação) - Programa de Pós-Graduação em Educação, Universidade de São Paulo, São Paulo, 2012.

DUTRA JÚNIOR, A. F. et al. Plano de carreira e remuneração do magistério público: LDB, Fundef, diretrizes nacionais e nova concepção de carreira. Brasília, DF: MEC, 2000.

GEMAQUE, R. M. O. Financiamento da educação - O Fundef na educação do estado do Pará: feitos e fetiches. 2004. Tese (Doutorado em Educação) - Programa de PósGraduação em Educação, Universidade do Estado de São Paulo, São Paulo, 2004.

GUTIERRES, D. V. G. A municipalização do ensino no município de Altamira/PA e suas implicações para a democratização educacional. 2010. 367 f. Tese (Doutorado em Educação) - Universidade Federal do Rio Grande do Sul, Porto Alegre, 2010.

MEIRELLES, H. L. Direito Administrativo brasileiro. 15. ed. São Paulo: Revista dos Tribunais, 1990.

MONLEVADE, J. A. C. Valorização salarial dos professores: o papel do piso salarial profissional nacional como instrumento de valorização dos professores da educação básica pública. 2000. 317 f. Tese (Doutorado em Educação) - Programa de Pós-Graduação em Educação, Universidade Estadual de Campinas, Campinas, 2000.

OLIVEIRA, D. A.; ASSUNÇÃO, A. A. Condições de trabalho docente. In: OLIVEIRA, D. A.; DUARTE, A. M. C.; VIEIRA, L. M. F. (Org.). Dicionário: trabalho, profissão e condição docente. Belo Horizonte: UFMG, 2010. CD-ROM.

PINTO, J. M. R. Remuneração adequada do professor: desafio à educação brasileira. Retratos da Escola, Brasília, DF, v. 3, n. 4, p. 51-67, 2009.

SILVA, E. C. A Política salarial dos professores da educação básica e a política de fundos: Fundef e Fundeb em questão. Jornal de Políticas Educacionais, Curitiba, n. 8, p. 52-62, 2010. 
SILVA, R. M. O. Promoção, vencimento e avaliação de desempenho: o PCCR da Rede Municipal de Ensino de Natal (2004-2010). 2014. 225 f. Tese (Doutorado em Educação) - Programa de Pós-Graduação em Educação, Universidade Federal do Rio Grande do Norte, Natal, 2014.

\section{José Joaquim Martins Castro (Brasil, Belém, Pará) - Universidade Federal do Pará (UFPA)}

Mestre em Educação pela UFPA. Integrante do Grupo de Estudos e Pesquisas em Políticas Públicas para Educação Básica (Geppeb). Atualmente é professor efetivo da Secretaria de Educação do Estado do Pará e da Secretaria Municipal de Educação de Cametá.

Lattes: <http://lattes.cnpq.br/5696725295275433>.

E-mail: <jucacastro@hotmail.com>.

\section{Fabrício Aarão Freire Carvalho (Brasil, Belém, Pará) - Universidade Federal do Pará (UFPA)}

Pós-Doutorando em Educação pela Universidade Federal do Paraná (UFPR). Atualmente é professor adjunto III do Núcleo de Estudos Transdisciplinares em Educação Básica (NEB) da UFPA e professor associado da Associação Nacional de Política e Administração Educacional (Anpae) e da Associação Nacional de Pesquisa em Financiamento da Educação (Fineduca). Coordena o Grupo de Estudos e Pesquisas em Políticas Públicas para a Educação Básica (Geppeb).

Lattes: <http://lattes.cnpq.br/6240386868511581>.

E-mail: <fafc33@gmail.com>.

Recebido em 29 de abril de 2018.

Aceito em 15 de outubro de 2018. 